\title{
INTERPOLATION OF COMPACT OPERATORS IN SPACES OF MEASURABLE FUNCTIONS
}

\author{
EVGENIY PUSTYLNIK
}

\begin{abstract}
It is shown that one-sided interpolation of compactness property is possible by any method on the class of pseudo-lattices, i.e., spaces of measurable functions, where the operators $P_{D} f=f \chi_{D}$ are uniformly bounded. Analogous results are shown for sequence spaces, ordered quasinormed Abelian groups and even extended to abstract Banach couples, satisfying some weak approximation hypothesis.
\end{abstract}

Mathematics subject classification (2000): 46B70, 46E30.

Key words and phrases: Interpolation, compact operators, lattice, approximation hypothesis.

\section{REFERENCES}

[1] N. AronsZajn, E. Gagliardo, Interpolation spaces and interpolation methods, Ann. Mat. Pura Appl. 68 (1965) 51-118.

[2] JU. A. BRUDNYI, N. JA. KRUGLJAK, Interpolation functors and interpolation spaces, vol. 1, North-Holland, Amsterdam, 1991.

[3] F. CoBos, M. CWIKel, P. Matos, Best possible compactness results of Lions-Peetre type, Proc. Edinburgh Math. Soc. 44 (2001) 153-172.

[4] F. Cobos, L. M. Fernández-Cabrera, A. Martínez, Complex interpolation, minimal methods and compact operators, Math. Nachr. 263-264 (2004) 67-82.

[5] F. Cobos, L. M. FernándeZ-CABrera AND A. Martínez, Compact operators between $K$ - and $J$-spaces, Studia Math. 166 (2005) 199-220.

[6] F. COBOS AND J. PEETRE, Interpolation of compactness using Aronszajn-Gagliardo functors, Israel J. Math. 68 (1989) 220-240.

[7] M. CWIKEL, Real and complex interpolation and extrapolation of compact operators, Duke Math. J. 65 (1992) 333-343.

[8] M. CWIKel, N. KaLTON, Interpolation of compact operators by the methods of Calderón and Gustavsson-Peetre, Proc. Edinburgh Math. Soc. 38 (1995) 261-276.

[9] M. CWiKel, N. KRUGLJaK, M. MASTYŁo, On complex interpolation of compact operators, Illinois J. Math. 40 (1996) 353-364.

[10] M. A. KRASNOSELSKII, On a theorem of M. Riesz, Dokl. Akad. Nauk SSSR 131 (1960) 246-248; English transl. in Soviet Math. Dokl. 1 (1960) 229-231.

[11] G. G. LORENTZ, T. SHIMOGAKI, Interpolation theorems for the pairs of spaces $\left(L^{p}, L^{\infty}\right)$ and $\left(L^{1}, L^{q}\right)$, Trans. Amer. Math. Soc. 159 (1971) 297-221.

[12] M. MASTYŁO, Interpolation of compact operators, Functiones et Approximatio 26 (1998) 293-311.

[13] J. PeETRE, G. SPARR, Interpolation of normed Abelian groups, Ann. Mat. Pura Appl. 92 (1972) 217-262.

[14] A. Persson, Compact linear mappings between interpolation spaces, Ark. Mat. 5 (1964) 215-219.

[15] T. SCHONBEK, Interpolation of compact operators by the complex method and equicontinuity, Indiana Univ. Math. J. 49 (2000) 1229-1245.

[16] R. SHARPLEY, Interpolation theorems for compact operators, Indiana Univ. Math. J. 22 (1973) 965-984. 